\title{
Assessment of the postdoctoral training needs of the osteopathic medical profession, 1987 to 1996
}

\author{
RALPH L. WILLARD, D.o. \\ Fort Worth, Texas \\ W. DOUGLAS WARD, Ph.D. \\ Chicago, Illinois
}

The environment surrounding the practice of medicine is changing dramatically. A glut of practicing physicians and a movement of physicians from private practices into corporate environments has been projected. Students graduating from medical schools are increasingly finding themselves at best in postdoctoral training programs that do not prepare them for this environment, or at worst without postdoctoral training available. Therefore, in 1985, the American Osteopathic Association Board of Trustees appointed a Task Force on Postdoctoral Training, charged with assessing factors affecting today's training programs and with projecting the future clinical training needs of the profession.

The Task Force, with the aid of the AOA Department of Education, interviewed leaders in the osteopathic medical profession and its affiliates, compiled and analyzed an information data base for osteopathic postdoctoral medical training, and researched sources of funding for postdoctoral training programs. A summary of the results of this work are contained in this paper.

The complete study had several aspects. This article focuses on the Task Force purpose, certain statistical projections, and the ultimate recommendations. The financial summary is abstracted from a position paper prepared by Howard Collier, LLD.

\section{Task Force objectives and methodology}

The Task Force was appointed by the Board in July 1985 at the request of the Committee on Postdoctoral Training. The charge of the Task Force was as follows: (1) To identify emerging issues that might have a positive or negative impact on osteopathic medical internship and residency training; (2) To assess the postdoctoral training needs of the profession through 1996; (3) To develop recommendations on the quality and availability of postdoctoral training programs in the osteopathic medical profession.

Members of the Task Force were selected to reflect a cross section of the profession. They included representatives from osteopathic medical colleges, the Committee on Postdoctoral Training, the AOA Board of Trustees, the Council on Federal Health Programs, the osteopathic specialty colleges, the Association of Directors of Medical Education, and the osteopathic hospital system. The members and staff of the Task Force are shown in Table 1.

The Task Force first met on November 22-3, 1985, to define its methodology.

The procedures used by the Task Force to carry out its charge were as follows:

(1) Needs assessment review. A Delphi study was used to analyze opinions on the postdoctoral training needs of the profession and the major factors affecting potential problems and solutions.

(2) Leadership interviews. The Task Force interviewed a select group of leaders in policy development to gather information on identified osteopathic medical education issues.

(3) Data base review. The AOA Department of Education summarized the existing data on osteopathic postdoctoral medical training to identify trends.

(4) Policies and procedures assessment. The Task Force analyzed current AOA postdoctoral training policies and procedures.

(5) Financial summary. The Task Force commissioned a report on sources of funding for osteopathic postdoctoral medical training to determine the potential effects of each funding alternative on program maintenance and development.

It met again on January $18-9,1986$, to draft statements and select participants. In May 1987 a summary of the information collected was distributed to Task Force members. The Task Force met for the last time on June 13, to develop a series of recommendations for presentation to the AOA Board of Trustees on July 23.

This report summarizes the results of the Delphi study, the statistical data, and the financial report. The leaderships' interviews, are presented separately. Finally, the Task Force recommendations are given. 
TABLE 2. PARTICIPANTS IN DELPHI STUDY.

Richard A. Anderson, D.O.

William G. Anderson, D.O.

Oscar J. Bailes, D.O.

Elmer C. Baum, D.O.

John W. Becher, Jr., D.O.

Wayne Beyerly

James H. Black, D.O.

Laurence E. Bouchard, D.O.

William Cairns

Dale Carrison, D.O.

Anthony G. Chila, D.O.

Anthony J. Cortese, D.O.

Gilbert E. D'Alonzo, Jr., D.O.

Dale Dodson, D.O.

Clare W. Elliott, D.O.

Harry B. Elmets, D.O.

Laurie Patterson Elwell, D.O.

A. Archie Feinstein, D.O.

Matthew Freund, Ph.D.

Kenneth P. Glinter, D.O

Robert J. George, D.O.

Murray Goldstein, D.O.

Michael B. Grossman, D.O.

Allen W. Jacobs, D.O., Ph.D.

Russell Jenkins, D.O.

Bob Jones

Thaddeus Kawalek, Ph.D.

Joseph V. Koehler, D.O.

Melvin M. Kolb, D.O.

Harry P. Kornhiser, D.O.

Irvin Korr, Ph.D.

Floyd Krengel, D.O.

Warren Lawless

Robert L. Litchfield, D.O.

Richard C. MacDonald, D.O.

Ella J. Marsh, D.O.

Mervin E. Meck, D.O.

Michael K. Murphy, D.O.

Frank J. Myers, D.O.

Joseph J. Namey, D.O.

Eugene A. Oliveri, D.O.

Gary J. Packin, D.O.

Michael Patterson, Ph.D.

Ray E. Piper, D.O.

Philip Pumerantz, Ph.D.

Claude G. Rainey

Stanislaus Roberto, D.O.

Mark Russell

Thomas F. Santucci, Jr., D.O.

Stanley Schiowitz, D.O.

William L. Smith, D.O.

Joseph W. Stella, D.O.

James R. Stookey, D.O.

Peter Tilley, D.O.

John A. Voorhees, D.O.

Jon F. Wills

Stanley N. Wilson, D.O

Walter Lynn Wilson, D.O.

Jack R. Wolfe, D.O.

Douglas L. Wood, D.O.

Affiliation*

State

AODME

AOA Board/House

Pennsylvania

COMP

AOA

ACOEP/AOBEM

California

AOHA

AMOPS/COPT/AOA House

AOA Board/House

AOHA/COPT

CSCP/COMP/AOA House

Bureau of Research/AAO

ACOOG

Bureau of Research

AOA House

ACOS/COPT

AOBD/Advisory Board

CSCP/CCOM/AOA House

Licensing Board/COC/AOA House

Bureau of Research/UMDNJ

AODME

AODME/COPT

Public Health

ACOOG

AACOM/KCOM

ACOS/TCOM

Oklahoma Osteopathic Association

Pennsylvania

Pennsylvania

Washington

Rhode Island

Iowa

California

Ohio

Oregon

Texas

Minnesota

Florida

Iowa

Illinois

Pennsylvania

New Jersey

Michigan

Ohio

Maryland

New Jersey

Missouri

Texas

Oklahoma

AACOM/CCOM

ACOI/NBOE/COPT

AMOPS/AOA House

AOBGP/WVSOM

TCOM

AOA House

WOMA

AODME/CCOM

$\mathrm{AAO} / \mathrm{COHA}$

ACOP

AOA Board/House

Illinois

Pennsylvania

Colorado

West Virginia

Texas

New Jersey

Washington

Illinois

Maine

Florida

Florida

Florida

Ohio

AACOM/OUCOM

SECOM/COC/AOA House

ACOI/COPT/AOA House

Florida

Michigan

New Jersey

Ohio

OUCOM

ACGP/COPT/AOA House

Colorado

California

Texas

Michigan

AOHA/TCOM

AOBP

AOHA/UMDNJ

UMDNJ/NBOE

AACOM/NYCOM

AOBOS

AOA Board/House

KCOM/AAO

PCOM

AODME

Ohio Osteopathic Association

AOA Board/House

AOA Board/House

OCOMS

AODME

New Jersey

New Jersey

New York

Arizona

Pennsylvania

Missouri

Pennsylvania

Oklahoma

Ohio

Indiana

Oklahoma

Oklahoma

Michigan

*Key to abbreviations

AACOM American Association of Colleges of Osteopathic Medicine; AAO-American Academy of Osteopathy; ACOEP-American College of AACOMathic Emergency Physicians; ACOI-American College of Osteopathic Internists; ACOOG-American College of Osteopathic ObstetriOsteopathic Emergency Physicians; ACOI-American College of Osteopathic Internists, ACOOG-Alcan - Asteopathic Surgeons; AMOPS cians and Gynecologists; ACOP-American College of Osteopathic Pediatricians; ACOS-American College of Osteopathic Surgeons; AMOPSAssociation of Military Osteopathic Physicians and Surgeons; AOBD-American Osteopathic Board of Dermatology; AOBEM-American Osteopathic Board of Emergency Medicine; AOBGP-American Osteopathic Board of General Practice; AOBOS-American Osteopathic Board of Orthopedic Surgery; AOBP-American Osteopathic Board of Pathology; AODME-Academy of Osteopathic Directors of Medical Education; AOHA - A merican Osteopathic Hospital Association; CCOM-Chicago College of Osteopathic Medicine; CME - Committee on Medical Education: COC - Committee on Colleges; COHA - Committee on Hospital Accreditation; COMP - College of Osteopathic Medicine of the Pacific; COPTCOC-Committee on Colleges, COHA Conste o Osteopathic Medicine; Committee on Postdoctoral Training; CSCP-Council of Student Council Presidents; KCOM-Kirksville College of Osteopathic Medicine; NBOE-National Board of Osteopathic Examiners; OCOMS - Oklahoma College of Osteopathic Medicine and Surgery; OUCOM-Ohio University College of Osteopathic Medicine; PCOM-Philadelphia College of Osteopathic Medicine; SECOM - Southeast College of Osteopathic Medicine: TCOM_Texas College of Osteopathic Medicine; UMDNJ-University of Medicine and Dentistry of New Jersey; WOMA-Washington Osteopathic Medical Association; WVSOM-West Virginia School of Osteopathic Medicine. 


\section{Internship training programs}

During the 1980 s, the number of AOA-approved intern training programs has grown 46 percent, beginning with a total of 1,114 positions in 1980-1 and growing to a total of 1,632 positions in 1986-7. Twenty-six states have one or more AOA-approved intern training programs. A concomitant growth in number of participating hospitals also has occurred (95 in 1981 versus 120 in 1986).

The pattern of available positions indicates that 84 percent of funded internship positions are located in ten states, six of which are in the northeast/north midwest region of the United States (Table 3). The majority of growth has occurred in states that had internship programs established by 1980 , although three states that currently have programs (Massachusetts, New Mexico, and West Virginia) did not have programs in that year. The largest single increment of growth occurred in New York, where 183 positions were added since 1980 . In addition, five states had an increase of 40 or more positions (Table 4). On the other hand, Michigan and New Jersey had fewer positions in 1986 than they did in their peak years. In 1984-5, Michigan had 288 slots compared with 278 in $1986-7$, and New Jersey has lost one slot from its peak of ninetynine in 1984-5.

Finally, the locations of colleges of osteopathic medicine had a significant impact on the location of internship training slots. The fourteen states with colleges account for ninety-seven percent of the total increase in positions (495 of 518 new positions).

\section{Residency programs}

Osteopathic medical residency programs have grown steadily from 1981-2 to 1986-7 (Table 5). There has been a total increase of 316 positions ( 27 percent) during that time.

Those practice areas in which the greatest increment has occurred are general practice (total increase of 139 positions) and internal medicine (32 positions). The only change in the majority of specialty programs has been an increase in the numbers of available AOA-approved positions. New specialties and subspecialties in which positions have been created since 1981-2 include diagnostic ultrasound, hematology/oncology, neonatal medicine, neuroradiology, nuclear radiology, and general vascular surgery.

The states with the greatest number of approved residency positions reflect primarily the influence of colleges of osteopathic medicine. Michigan, Pennsylvania, Ohio, New Jersey, and Illinois have the greatest percentage of approved residency positions (90 percent) and the greatest percentage of

\begin{tabular}{|lcc|}
\hline \multicolumn{3}{|l|}{ TABLE 3. LEADING STATES WITH FUNDED INTERNSHIP POSI- } \\
TIONS. \\
\hline & \multicolumn{2}{|c|}{ Positions } \\
State & Number & \% of total \\
\hline Michigan & 240 & 17 \\
Pennsylvania & 197 & 14 \\
Ohio & 161 & 12 \\
New York & 104 & 7 \\
Florida & 99 & 7 \\
Illinois & 86 & 6 \\
New Jersey & 86 & 6 \\
Missouri & 73 & 5 \\
Oklahoma & 66 & 5 \\
Texas & 68 & 5 \\
\hline
\end{tabular}

TABLE 4. INCREASES IN INTERNSHIP POSITIONS OF FORTY OR MORE.

\begin{tabular}{|lc|}
\hline State & $\begin{array}{c}\text { Actual growth } \\
\text { since } 1980-1\end{array}$ \\
\hline New York & 183 \\
Pennsylvania & 63 \\
Florida & 55 \\
New Jersey & 42 \\
California & 40 \\
Illinois & 40 \\
\hline
\end{tabular}

programs (56 percent). Additionally, these five states have 52 percent of approved osteopathic hospitals. Twenty-one states have at least one residency program. Finally, there are no programs in a West Coast state other than one general practice residency.

The number of residents obtaining AOA-approved positions in the 12 specialties noted in Table 5 has grown by 422 since 1981-2. The areas in which there was a decrease in positions and residents during that same period were infectious diseases, nuclear medicine, pediatrics, and thoracic/cardiovascular surgery.

\section{Financial summary}

In the fall of 1970 , six colleges of osteopathic medicine had a total entering class size of 577 and a total enrollment of 2,151. By the fall of 1987, the number of colleges of osteopathic medicine had grown to fifteen and the total entering class size had increased to 1,665 with a concomitant growth in total enrollment to 6,481. In June 1971, 473 D.O. degrees were awarded; in June 1988, approximately 1,567 D.O. degrees will be conferred.

In 1971, there were about 556 funded internship positions available for 473 graduating D.O.s, whereas in 1988 there should be approximately 1,425 funded positions for the 1,567 D.O. graduates. Thus, the new schools and increased enrollments may have placed greater stress on available clinical facilities and clinicians.

Each of the fifteen colleges has a distinctive 4year curriculum, but they tend to have 2-years of 


\begin{tabular}{|c|c|c|c|c|c|c|}
\hline \multirow[b]{2}{*}{ Specialty/subspecialty } & \multicolumn{3}{|c|}{ Positions } & \multicolumn{3}{|c|}{ Residents } \\
\hline & $1981-82$ & $1986-87$ & Increase & $1981-82$ & $1986-87$ & Increase \\
\hline Anesthesiology & 113 & 118 & +5 & 36 & 74 & +38 \\
\hline Cardiology & 14 & 23 & +9 & 8 & 9 & +1 \\
\hline Emergency medicine & 46 & 70 & +24 & 23 & 50 & +27 \\
\hline General Practice & 187 & 326 & +139 & 56 & 200 & +144 \\
\hline Internal medicine & 314 & 346 & +32 & 189 & 270 & +81 \\
\hline Obstetrics/gynecology & 101 & 124 & +23 & 67 & 105 & +38 \\
\hline Ophthalmology & 29 & 40 & +11 & 20 & 24 & +4 \\
\hline Orthopedic surgery & 120 & 125 & +5 & 93 & 112 & +19 \\
\hline $\begin{array}{l}\text { Otorhinolaryngology/orofacial } \\
\text { plastic surgery }\end{array}$ & & 49 & +29 & 14 & 33 & \\
\hline 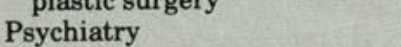 & $\begin{array}{l}20 \\
11\end{array}$ & 36 & +25 & 2 & 20 & $\begin{array}{r}1 \\
+\quad 18\end{array}$ \\
\hline General surgery & 209 & 215 & +6 & 116 & 148 & +32 \\
\hline Urological surgery & 27 & 35 & $\begin{array}{r}8 \\
+\quad 8 \\
\end{array}$ & 17 & 18 & $\begin{array}{r}1 \\
+\quad 1 \\
\end{array}$ \\
\hline Totals & 1191 & $\overline{1507}$ & +316 & 641 & 1063 & +422 \\
\hline
\end{tabular}

basic science instruction and 2 years of clinical instruction that includes externships and/or clerkships. Reflecting the growth of schools and students is an increase in the number of candidates in the 2 clinical years from 1,075 in $1970-1$ to 3,240 in 1987-8.

Most, although not all, states require the D.O. degree plus completion of the internship year before a D.O. may enter practice. However, there is growing evidence that hospitals and group practices are requiring training beyond the single internship year. It is clear that 5 or more years of osteopathic medical education is a minimum requirement in the present and will continue for the future.

The AOA Department of Education Committee on Colleges has never had jurisdiction over the required fifth year, and college presidents and deans differ in their perceptions of responsibility for that year. At various times and at various schools the Committee has detected weakness in quality control of the existing externship/clinical clerk years, but it has not addressed internships. In addition, the AOA Central Office structure and staffing of the AOA Department of Education have not been adequate to have field representatives work with the various deans to expand the availability and number of quality clinical clerkships and internships. This is a major issue of AOA budget and finance.

While the profession is growing, the nation is moving toward and all-payers form of reimbursement. However, there is little evidence that hospitals will not be reimbursed for substantial numbers of interns/residents in the several primary care specialties. In contrast, medical education was placed on notice several years ago that education cost reimbursements would be reduced or curtailed for subspecialty training that required more years than those of the primary care specialties.

The steady decline in inpatient hospital days and the steady growth of outpatient visits are current realities. Hospitals will be hiring interns and residents as patient care employees while specialty boards and AOA constituencies will be pressing for improved training standards.

\section{Conclusion}

There is a greater danger in overreaction to changes in Graduate Medical Education reimbursement than there is in underreaction. The temptation is great-and must be repressed-to approve allopathic training site programs through a cosmetic appointment of a D.O. director/chairman who neither directs nor chairs. However, we must find opportunities in which a D.O. director of medical education does dictate education policy in a mixed-staff setting.

\section{Discussion}

The rapid growth of the osteopathic medical profession coupled with recent changes in federal health care reimbursement policy have created an immediate crisis in osteopathic postdoctoral training. The respondents to the Delphi questionnaire anticipate that these events, manifested as increased numbers of osteopathic medical graduates, the advent of DRGs, and the growth of HMOs, PPOs, and proprietary hospital chains, have set in motion a permanent restructuring of the health care industry, which will have a serious impact on osteopathic graduate medical education for the next decade.

The osteopathic medical profession must respond to this changing environment in an innovative and 
flexible manner. The major ideas expressed by the osteopathic leaders and educators, who participated in the Task Force study, concern the course of action the osteopathic medical profession should take regarding postdoctoral training response to this changing environment. Their views can be summarized as follows:

(1) The role of ambulatory clinic facilities as postdoctoral training sites should be expanded. The cost-containment policy mandated by the federal government and expressed by HMOs, PPOs, and corporate health care facilities is resulting in severely reduced hospital occupancy rates with fewer patients available to train interns and residents in a traditional setting.

It is suggested, therefore, that during their postdoctoral training interns and residents be given increased time and experience in ambulatory settings where the patient volume is increasing. This change also will allow programs to reflect more accurately the shift from inpatient to outpatient treatment by practitioners, and thus better prepare physicians for the practice of medicine in today's environment.

Osteopathic medical teaching programs will continue to be sponsored for the most part by AOAaccredited institutions. However, these institutions should begin to design programs that incorporate rotations in a wider variety of clinical settings including community health centers, physician's offices, and geriatric centers. Field personnel should be added to the Department of Education to help hospitals and colleges seek ambulatory teaching sites that meet Committee on Postdoctoral Training (COPT) standards for intern training. COPT should consider changes in rotational requirements for intern training that will permit more ambulatory based training and more accurately reflect current modes of patient care. Despite this shift in settings, however, training experiences must remain structured educational activities supervised by qualified faculty.

(2) The osteopathic medical profession must develop a mechanism to establish an alternate funding base for postdoctoral programs. Several respondents in the Delphi study believe that while Medicare is not expected to continue to support graduate medical education at existing levels, the osteopathic medical profession should remain actively involved in influencing the government's financial policy in this area. A cooperative lobbying effort between the AOA, American Association of Osteopathic Medicine (AACOM), American Osteopathic Hospital Association (AOHA), and other health care organizations is suggested.

With the base of Medicare "pass-through" monies eroding, however, the devilopment of alter- native funding sources is considered necessary. Suggestions include: increased state support, feefor-service revenue from patient care provided by interns or residents, reimbursement by Medicaid, Medicare, and third party payers for health care provided by "units of service" comprised of practicing physicians and residents, and tuition from students for intern training with the internship redefined as the fifth year of medical school. Neither the reduction of intern or resident stipends nor the payment of capitation fees by colleges to hospitals is advocated.

(3) The AOA should immediately improve and augment its postdoctoral training program inspection, evaluation, and consultation process and functions. Osteopathic hospitals will remain viable as training facilities only if the quality of educational programs is maintained at a high level. The AOA Department of Education, in conjunction with the AOA educational committees and specialty colleges, should provide training for program directors and inspectors and expand its technical consultative services for hospitals and colleges, to facilitate the development of new and expanded internships and residencies, and insure adherence to high standards.

(4) The osteopathic rotating internship should be maintained and adapted to be more responsive to changing health care trends and practices. Those interviewed believed that the rotating internship is a valuable part of osteopathic medical training that should not be abandoned. It is important for new physicians to gain experience in treating patients across a broad spectrum of medical disciplines so that they will be better prepared to diagnose illness and refer patients for appropriate treatment. Suggestions for modification and improvement center on increased flexibility to make the internship more practical administratively, to allow a wider range of experiences, to increase practice opportunities, to permit geographic redistribution, and to better reflect practice realities.

(5) Osteopathic medical principles and practices must continue to be taught in intern and residency training programs. The respondents in the Delphi study concur that osteopathic postdoctoral training programs need to maintain their unique osteopathic identity and that no basic osteopathic principles should be abandoned to develop additional funded positions. They are particularly concerned about the transmission of osteopathic principles and practices in programs at allopathic and mixed-staff facilities.

(6) Primary care should continue to be a major and essential emphasis of the osteopathic postdoctoral training programs. The AOA should also continue to approve and develop postdoctoral training 
programs in other specialties to provide a full spectrum of health care. The leaders interviewed agree that the emphasis of osteopathic internship and residency programs should remain on primary care. They expect the need for primary care physicians to grow because of the increasing concern for cost containment and use of prepaid provider networks.

The federal government has warned of severely curtailed reimbursement for subspecialty training requiring more years of training then the primary care specialties. The Delphi study respondents speculate that in the future the federal government might reimburse hospitals only for the costs associated with internship and primary care residency training in accordance with national priorities.

(7) The AOA should develop further consultant services to aid the innovation, evaluation, and expansion in postdoctoral training. The respondents to the Delphi study identified many areas in which osteopathic medical colleges and hospitals will have to introduce sweeping changes to insure the continuation of high quality osteopathic postdoctoral training. These institutions will need substantial technical assistance to plan and implement those changes. They also proposed innovative financial and administrative solutions to existing problems that will require substantial testing and experimentation for full development and refinement.

The AOA Department of Education should be staffed with sufficient qualified personnel to work with the colleges and hospitals on a consultative basis to facilitate these changes and conduct the necessary programmatic research and testing.

(8) The AOA Department of Education shall expand and develop further the data collection, analysis, and reporting process set in motion by the Task Force on Postdoctoral Training. The health care environment is going to continue to change radically for the next decade and the osteopathic medical profession will need to be able to monitor and act responsively to those changes to take advantage of new opportunities, anticipate potential problems, and continue to provide relevant postdoctoral training. The AOA Department of Education is suggested as the appropriate unit to take responsibility for that activity, although further resources will be required.

(9) The osteopathic medical profession should position itself to benefit from the expulsion of foreign medical graduates from allopathic postdoctoral training programs. The positions in allopathic hospitals that have been filled by foreign medical graduates may soon be open to osteopathic physicians. This policy change is expected to stimulate the active recruitment of osteopathic medical gradu- ates by allopathic facilities to fill their house staff positions. This changing political situation is likely to set off fierce competition within the medical education community for the monies formerly assigned to foreign medical graduates. It is recommended that the osteopathic medical profession position itself to reap the maximum benefit.

\section{Conclusion}

On the basis of the data and views summarized in this report, the Task Force on Postdoctoral Training recommended the following actions to the AOA Board of Trustees at the 1987 Annual Meeting in Chicago.

(1) Keep the number of graduating osteopathic students consistent with the number of AOA-approved intern positions. This recommendation reflects the current deficit of funded internship positions available for osteopathic medical school graduates. The Task Force considers that the medical schools, training hospitals, and other facilities have the joint responsibility to meet the needs of graduating students by reductions in class size and/ or continuing development of training positions.

(2) Maintain the osteopathic rotating internship, adapting it as necessary in response to changing health care trends and practices. The Task Force finds overwhelming support for maintenance of the rotating internship. However, careful study and modification of the program is needed continually to keep the experience practical and useful.

(3) Maintain primary care as the major and essential emphasis of the osteopathic postdoctoral training programs. Because of the ever growing demand for primary care physicians and the anticipated reduction in government funding for subspecialty training, the Task Force recommends a continuing focus on primary care medicine in osteopathic postdoctoral training.

(4) Encourage and facilitate the increased use of ambulatory care facilities as postdoctoral training sites in AOA-approved internship and residency training programs. The Task Force recommends that an ad hoc committee with representatives from osteopathic hospitals and medical colleges be formed to consider changes in AOA policy and procedure that would accommodate expanded training in ambulatory care settings. This shift in training sites reflects the changing trends in medical care and thus will open new positions and result in more relevant preparation for practice.

(5) Initiate and conduct postdoctoral faculty development programs in osteopathic princples and practice. The Task Force considers it essential to incorporate educational input concerning the unique philosophy and skills of osteopathic medicine in all training settings, including non- 
osteopathic facilities. To accomplish this goal, the Task Force recommends that an ad hoc committee be charged with formulating a plan for the development of faculty training programs on the teaching of osteopathic principles and practices including strategies for funding, sponsorship, and location.

(6) Improve and augment the AOA postdoctoral training program inspection, evaluation, and consultation process and functions. To continue to improve the quality of postdoctoral training programs, the Task Force recommends that the AOA Department of Education, in conjunction with the AOA educational committees and specialty colleges, establish guidelines and requirements for the selection of program directors and inspectors, and provide training for both groups through workshops and self-study guides based on standardized learning objectives.

(7) Study and develop alternative funding for postdoctoral programs. On the basis of predictions that the Medicare funding base for postdoctoral training will continue to erode, the Task Force rec- ommends the formation of an ad hoc committee to investigate other means of financial support including increased state funding, fee-for-service revenues from patient care provided by interns and/or residents, reimbursement by third parties for "units of service" comprised of practicing physicians and residents, and tuition from students for intern training with internship redefined as the fifth year of medical school.

(8) Establish a task force to monitor the changing health manpower needs of the profession, identifying relevant areas for further study, and recommending appropriate action. The Task Force recommends that the profession continue to monitor the health care environment to anticipate and appropriately respond to changes in manpower needs, funding, and practice.

Dr. Ward is director of the AOA Department of Education, Chicago, Illinois. Dr. Willard is professor in the Department of Surgery at TCOM. He served as chairman of the Task Force on Postdoctoral Training. 


\section{When the Goal Is to Reduce Elevated Blood Cholesterol... .}
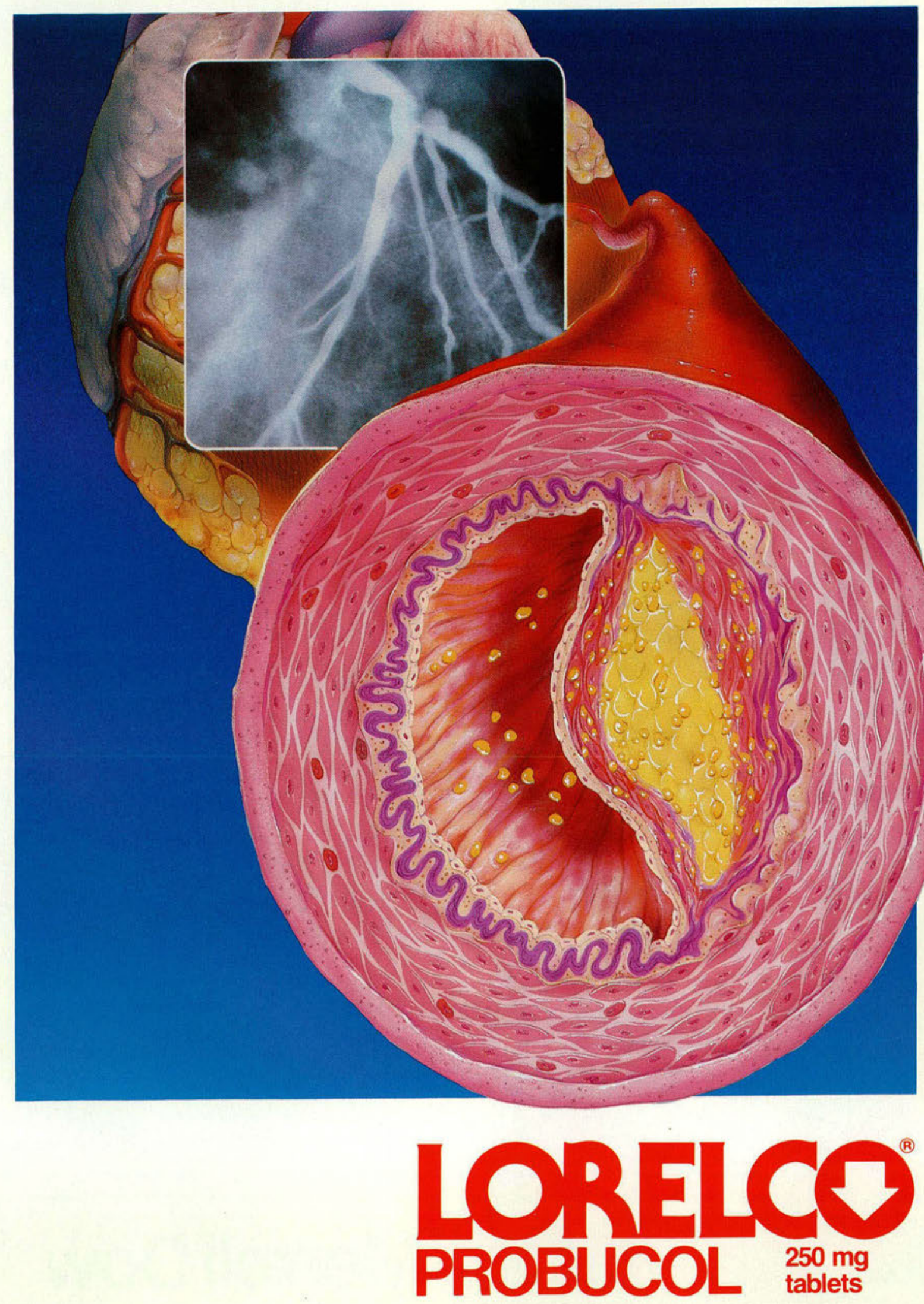


\section{Choose}
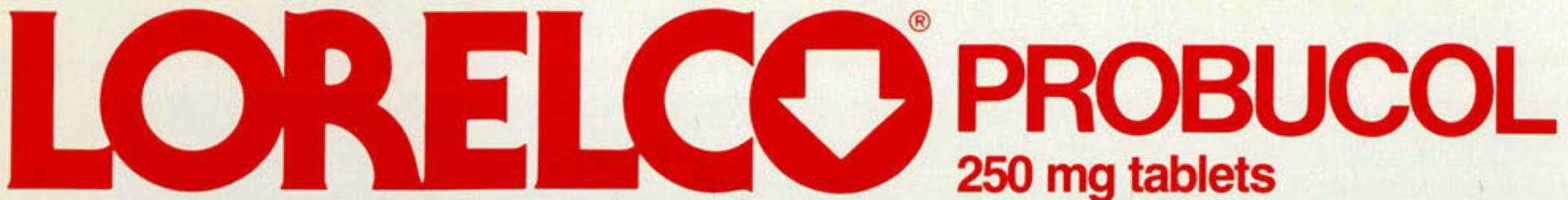

$250 \mathrm{mg}$ tablets

as an adjunct to diet
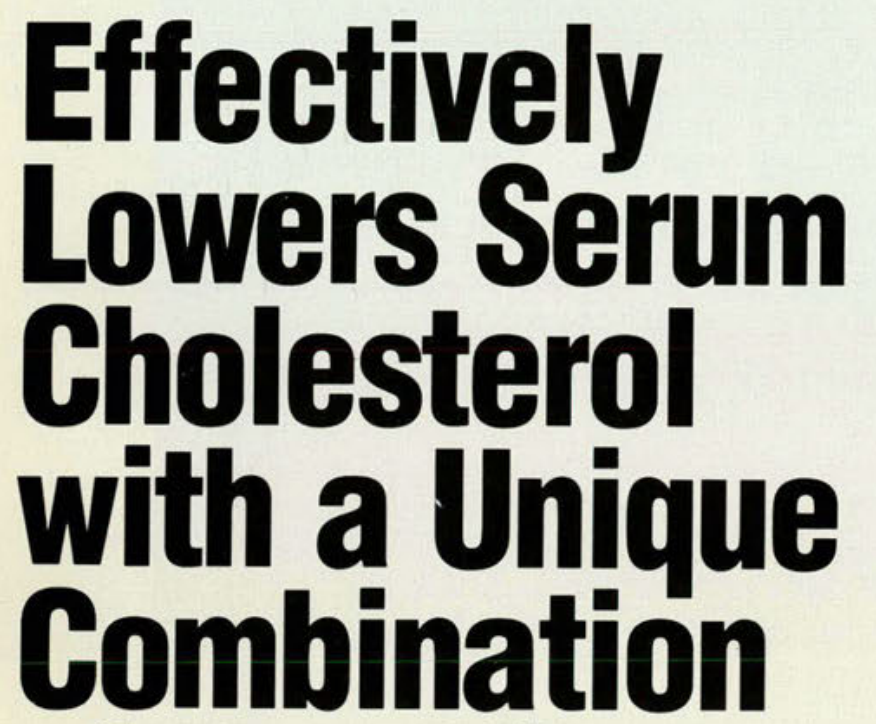

of Benefits

Consider the Whole Picture.

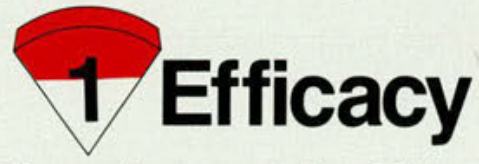

Lorelco works! You can prescribe it with confidence. Lorelco can virtually double the cholesterol-lowering efficacy of diet alone. ${ }^{1}$ Total cholesterol-lowering efficacy beyond diet ranges from $10.7 \%$ to $27 \%$ in reported studies. ${ }^{1-4}$

\section{0 years of outstanding Lorelco performance 5 \\ Now prescribed in 27 countries}

\section{Indications}

Lorelco is specifically indicated for the reduction of elevated serum cholesterol in patients with primary hypercholesterolemia who have not responded adequately to diet.

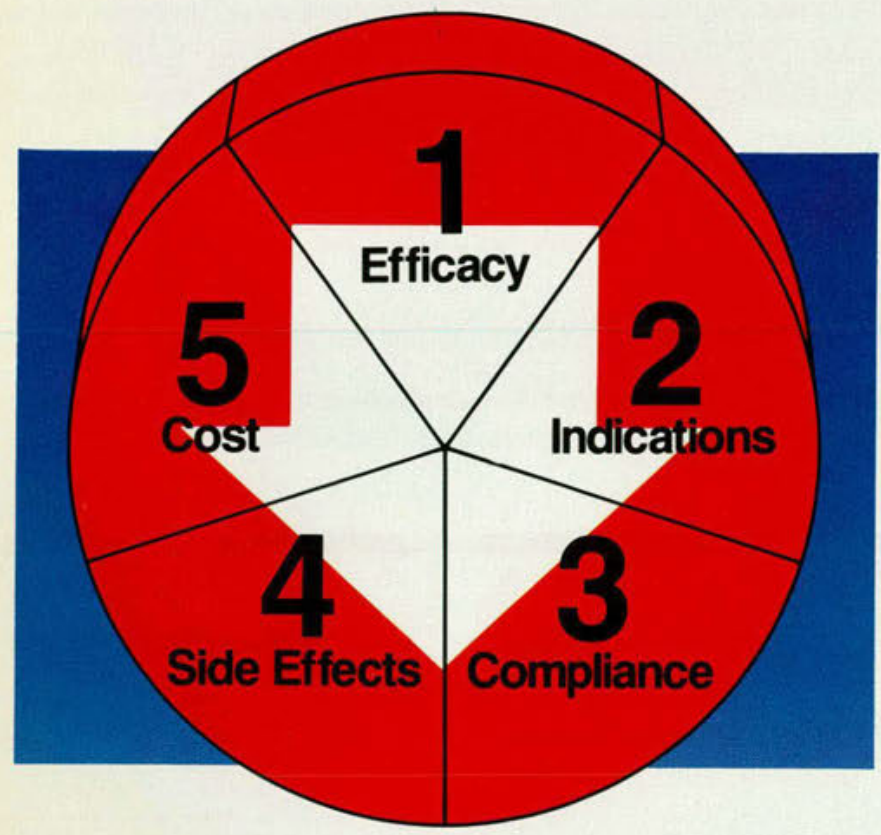




\section{Compliance}

The reasons for excellent compliance with Lorelco become clear with the taste and texture test.

This

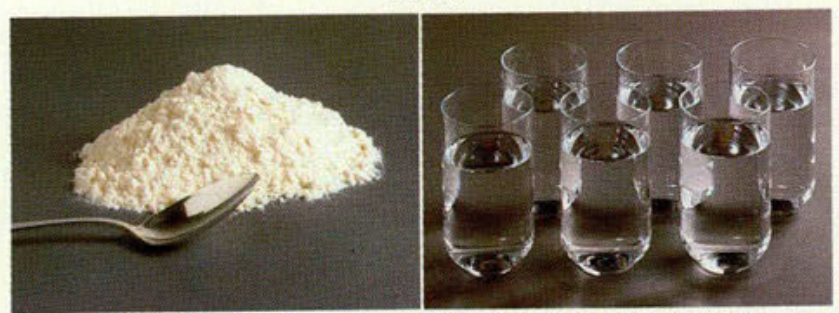

Questran daily dose (one 9-gram Water (2 to 6 ounces with each packet one to six times daily) packet)

or This

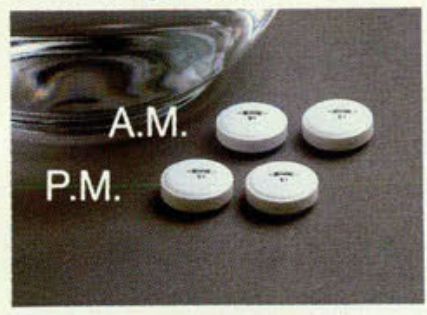

Lorelco daily dose (2 tablets twice daily with meals)
4 Side Effects

Lorelco side effects are generally tolerable and of short duration. Most frequent patient complaint is loose stools, which occur in about one in 10 patients and generally subside during therapy (see Prescribing Information for full discussion of side effects).

Lorelco is not an innocuous drug and strict attention should be paid to the Indications, Warnings, and Precautions.

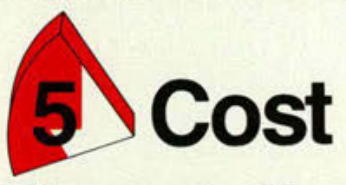

The cost of Lorelco is significantly lower than that of the resins, ranging from one-third to about one-half their average price. Cost can be a significant factor when therapy may have to be continued long-term, perhaps for years.

Tablet counts in a 7 year study of Lorelco indicated that patients took over $90 \%$ of their scheduled dosage. ${ }^{6}$

\section{Lorelco (probucol) presents a whole picture of hypercholesterolemia therapy.}

The effect of probucol-induced reduction of serum cholesterol or triglyceride levels or alteration of $\mathrm{HDL}$-cholesterol levels on morbidity or mortality has not yet been established. Several years may be required before ongoing long-term investigations will resolve this question.

Prescribing Information appears on the last page. 


\section{References:} 1. LeLorier J, et al: Diet and probucol in lowering cholesterol concentrations. Arch Int Med 137
1429-1434, 1977.

2. Mellies MJ, et al: Effects of probucol on plasma cholesterol, high and low density lipoprotein cholesterol and apolipoproteins A1 and A2 in adults with primary familial hypercholesterolemia Metabolism 29:956-964, 1980. 3. Polachek AA, et al: Probucol in the long-term treatment of hypercholesterolemia. Curr Med Res and
Opin 1:323-330, 1973.

\section{Lorelco ${ }^{\circledR}$ Tablets \\ (probucol tablets)}

CAUTION: Federal law prohibits dispensing without prescription.

DESCRIPTION: Lorelco (probucol) film-coated tabiets for oral administration contain $250 \mathrm{mg}$ of probucol per tablet. Each tatet also contains as inactive ingredients: corn starch, ethyicellulose, glycerin, hydroxypropyl cellulose, hydroxypropy

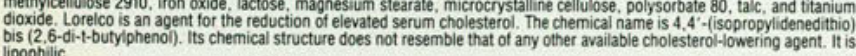

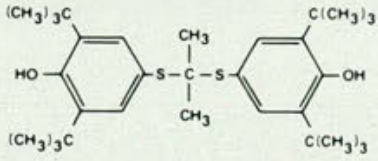

CLINICAL PHARMACOLOGY: Lorelco (probucol) lowers serum cholesterol and has relatively little effect on serum triglycerides. Patients responding to probucol exhibit a decrease in low density lipoprotein cholesterol. Cholesterol is reduced

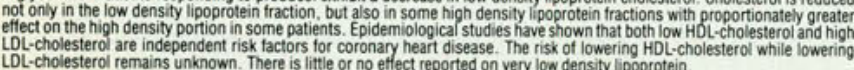

Studies on the mode of action of Lorelco indicate that it increases the fractional rate of catabolism of low density lipoproteins This effect may be linked to the observed increased excretion of fecal bile acids, a final metabolic patthway for the elimination o cholesterol from the body. Lorelco also exhibits inhibition of early stages of cholesterol synthesis and slight inhibition of

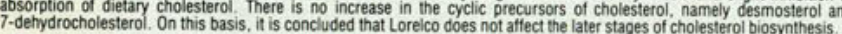
Absorption of Lorelco from the gastrointestinal tract is limited and variable. When it is administered with food, peak blood levels gradually increase over the first three to four months and thereafter remain tairly $\mathrm{mg}$.

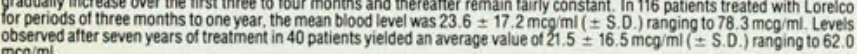

At the end of 12 months of treatment in eight patients, blood levels averaged $19.0 \mathrm{mcg} / \mathrm{ml}$. Six weeks after cessation of therapy, the average had fallen by 60 percent. After six months the average had fallen by 80 percent.

In December 1984 a National Institutes of Health Consensus Development Conference Pancli concluded that lowering definitely
elevated blood cholesterol levels (specifically blood levels of low-density linoprotein cholestercl) will reduce the risk of heart elevated blood cholesterol levels (specifically blood levels of low-density lipoprotein cholesterol) will reduce the risk of hear altacks due to coronary heart disease. The etitect of probucol-induced reduction or serum cholesterol or triglyceride levels or

INDICATIONS AND USAGE: Serious animal toxicity has been encountered with probucol. See WARNIINGS and ANIMAL
PHARMACOLOGY AND TOXICOLOGY sections. Probucol is not an innocuous drug and strict attention should be pad to the INDICATIONS and WARNINGS.

Drug therapy should not be used for the routine treatment of elevated blood lipids for the prevention of coronary heart disease. Dietary therapy specific for the type of hyperlipidemia is the initial treatment of choice. Excess body weight may be an importan disease such as hypothyroidism or diabetes mellitus should be looked for and adequately tratated. The use of drugs should be considered only when reasonable attempts have been made to obtain satisfactory results with non-drug methods. If the decision
ultimately is to use drugs, the patient should be instructed that this does not reduce the importance of adhering to diet. The The selection of patients for cholesterol-lowering drug therapy should take into account other important coronary risk factors
such as smoking, hypertension and diabetes mellitus. Consideration should be given to the efficacy, safety and compliance
tactors for each of the cholesterol-lowering drugs prior to selecting the one most appropriate for an individual patient. Lorelco may be indicated for the reduction of elevated serum cholesterol in patients with primary hypercholesterolemia (elevated low density lipoproteins) who have not responded adequately to diet, weight reduction and control of diabetes melitus. Loreico riglyceridemia, but it is not indicated where hypertriglyceridemia is the abnormality of most concern.

It is not always possible to predict from the lipoprotein type or other factors which patients will exhibit favorable results. Lipid levels should be periodically assessed. Small or transient changes in high density lipoprotein cholesterol may be due to The effect of probucol-induced reduction of serum cholesterol or triglyceride levels or alteration of HDL-cholesterol levels on morbidity or mortality due to coronary heart disease has not yet been established. Several years may be required before ongoing CONTRAINDICATIONS: (See also PRECAUTIONS.) Lorelco is contraindicated in patients who are known to have a

WARNINGS: SERIOUS ANIMAL TOXICITY HAS BEEN ENCOUNTERED WITH PROBUCOL IN RHESUS MONKEYS FED AN ATHEROGENIC DIET AND IN BEAGLE DOGS. (SEE ANIMAL PHARMACOLOGY AND TOXICOLOGY SECTION

Although Q-T prolongation can occur in patients on probucol, the arrtythmias observed in monkeys ted large doses of probuco
added to an atherogenic diet have not been reported in man; nevertheless, the tollowing precautions are deemed prudent:

1. At the start of treatment with Lorelco and throughout the treatment period, patients should be advised to adhere to a low

2. As part of an overall evaluation, a baseline, six month, and one year repeat ECG tracing should be considered. If marked

prolongation of the Q-T interval (after correction for rate) occurs, the possible benefits and risks should be carefully

ventricular arrthythmias.

No instances of increase in ectopy atributed to toretco have been reported. Horker, pate P

PRECAUTIONS

General: Because Loreico is intended for long-term administration, adequate baseline studies should be pertormed to repeated during the first few months of treatment and periodically thereafter. A tavorable trend in cholesterol reduction should be

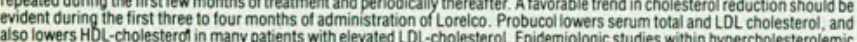
populations have shown that serum $\mathrm{HOL}$-cholesterol is an independent, inversely correlated, risk factor for coronary heart disease (see CLINICAL PHARMACOLOGY). Animal or human studies which could confirm or deny the hypothesis that drug induced alteration in $\mathrm{HDL}$-cholesterol affects cardiovascular risk have not been carried out. It is not known whether probuco:

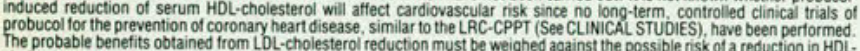
cholesterol when assessing the response of each patient receiving Lorelco treatment. If satisfactory lipid alteration is not

Information for Patients: The patient should be instructed to adhere to a prudent diet. Females should be cautioned against becoming pregnant for at least six months after discontinuing Lorelco and should not breast feed their intants during therapy
with Lorelco. Laboratory Tests: The physician should schedule periodic blood lipid determinations and should consider periodic
electrocardiograms. (See WARNINGS.) (lectrocardiograms. (See WARNINGS.)

Elevations of the serum transaminases (glutamic-oxalacetic and glutamic-pyruvic), bilirubin, alkaline phosphatase, creatine
phosphokinase, uric acid. blood urea nitrogen and blood glucose above the normal range were observed occasions in various patients treated with Loreico. Most often these were transient and or could have been related to the patient's clinical state or other modes of therapy. Although the basis tor the relationship between probucol and these
abnormalities is not firm, the possibility that some of these are drug-related cannot be excluded. In the controlled trials, the incidence of abnormal laboratory values was no higher in the patients treated with probucol than in the patients who received placebo. If abnormal laboratory tests persist or worsen, if clinical signs consistent with the abnormal laboratory tests develop,
or if systemic manifestations occur, probucol should be discontinued.

Drug interactions: The addition of clofibrate to probucol is not recommended since the lowering effect on mean serum levels
of either $\mathrm{LDL}$ or total cholesterol is generally not significantly additive and, in some patients, there may be a pronounced lowering of HDL-cholesterol. Neither oral hypoglycemic agents nor oral anticoagulants alter the effect of be a proiconounced on serum
cholesterol. The dosage of these agents is not usually modified when given with cholesterol diet admixed with probucol exhibited serious toxicity. Whe toxicity observed in monkeys has not been reported in
man. (See WARNINGS and ANIMAL PHARMACOLOGY AND TOXICOLOGY sections.)
4. Baker SG, et al: Treatment of homozygous familial hypercholesterolemia with probucol. S Afr Med J

5. Data on file, MERRELL DOW PHARMACEUTICALS INC. Cincinnati, Ohio 45215 6. McCaughan D: The long-term effects of probucol on serum cholesterol levels. Arch Int Med
141:1428-1432, 1981.

Carcinogenesis, Mutagenesis, Impairment of Fertility

In chronic studies of two years duration in rats, no toxicity or carcinogenicity was observed. These results are consistent with
the lack of any adverse effect on fertility and the negative findings in tests for motagenic activity in rats Pregnancy

Peratogenic Effects
Pregnancy - Category B: Reproduction studies have been pertormed in rats and rabbits at doses up to 50 times the human
dose, and have revealed no evidence of impaired fertility or harm to the fetus due to probucol. There are, however, no adequate and well-controlled studies in pregnant women. Because animal reproduction studies are not always predictive of human

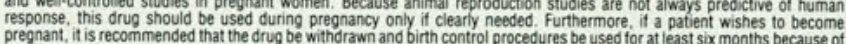
pregnant, it is recommended that the drug be withdrawn and birth control procedures be used for at least six months because of
persistence of the drug in the body for prolonged periods. (See CLINICAL PHARMACOLOG.) Labor and Delivery: The effect of Lorelco on human labor and delivery is unknown.

Nursing Mothers: It is not known whether this drug is secreted in human milk, but it is likely to be since such excretion has Pediatric Use: Safety and effectiveness in children have not been established.

ADVERSE REACTIONS

Gastrointestinal

作, fatulence, abdominal pain, nausea, vomiting, indigestion, gastrointestinal bleeding

Cardiovascula

Neurologic

dininess, paresthesias, insomnia, tinnitus, peripheral neuritis

Hematologic
eosinophlia

.

Dermatologic
rash, prurifus,

Genitourinary
impotency, nocturia

Ophthaimic

conjunctivitis, tearing, blurred vision

Endocrine

of multinodular goiter

Idiosyncrasies

An idiosyncratic reaction observed with init
vomiting and chest pain has been observed.

Other

DRUG ABUSE AND DEPENDENCE: No evidence of abuse potential has been associated with Lorelco, nor is there of psychological or physical dependence in humans.

OVERDOSAGE: There is a single report of a $15 \mathrm{~kg}$, three-year-old male child who ingested $5 \mathrm{gm}$ of probucol. Emesis was induced by ipecac. The child remained well, apart from a brief episode of loose stools and flatulence. No specific information
is available on the treatment of overdosage with Lorelco and no specific andodote is availabie. Probucol is not dialyzable. Treatment is symptomatic and supportive. Probucol has shown no identifiable acute toxicity in mice and rats. In these
animals the LO $L$ soral) is in excess of 5 gmikg of body weight.

DOSAGE AND ADMINISTRATION: For adult use only. The recommended and maximal dose is $500 \mathrm{mg}$ (two tablets of HOW SUPPLIED: Each white film-coated tablet contains $250 \mathrm{mg}$ probucol and is imprinted with the $00 \mathrm{~W}$ diamond trademark over the code number 51 .

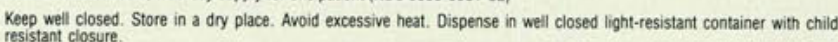
ANIMAL PHARMACOLOGY AND TOXICOLOGY: In thesus monkeys administration of probucol in diets containing
unusualiy high amounts of cholesterol and saturated fat resulted in the death of four of eight animals after several w weeks.
Premonitory syncope was trequently observed and was associated with a pronounced prolongation of the $Q-T$ intervals $(30$ to Premonitory syncope was frequently observed and was associated with a pronounced prolongation of the $Q-T$ intervals ( 30 to
50 percent associated with some prolongation in the $Q$.T interval in the cholesterol-ted monkey. A 75 msec or greater increase in $Q$. interval from control values was usually seen at $40 \mathrm{mcg} / \mathrm{mi}$ and above. Blood levels in humans receiving probucol average
approximately $20 \mathrm{mcg} / \mathrm{ml}$ and not uncommonly reach levels of $40 \mathrm{mcg} \mathrm{ml}$ and higher. Rhesus monkeys fed normal (low fatt chow and receiving probucol three to thirty times the human dose equivalent achieved blood levels only one-thiro those of many human subjects. No adverse effects were detected in these monkeys over an eight-year period of continuous drop

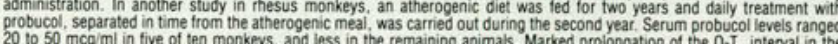
201050 mcg mli in five of ten monkeys, and less in the remaining animals. Marked prolongation of the $Q-T_{c} c$ interval in the electrocardiogram or syncopal behavior was never observed over the entire one-year treatment period. Regression of gross receiving probucol. It should be emphasized that both $\mathrm{HOL}$-cholesterol and $\mathrm{LDL}$-cholesterol were markedly reduced in this
regression study. During the pertormance of a two-year chronic study involving 32 probucol-treated dogs (beagles) there regression study. During the performance of a two-year chronic study involving 32 probucol-treated dogs (beagles) there
were 12 tatalities. Subsequent experiments have indicated that probucol sensitizes the canine myocardium to epinephrine. resulting in ventricular fibriliation in many dogs. Amnong the animal species in which probucol has been studied, the dog is
peculiar with respect to the phenomenon of sudden death due to the sensitization of the myocardium to epinephrine. In
contrast to findings in the dog. injections of epinephrine to probucol-treated monkeys did not induce ventricular fiorillation. In other studies, monkeys were given probucol either before and after, or only after myocardial intarction induced by coronary artery ligation. In these studies there was no difterence between probucol- and placceo- treated groups with respect to either
survival or detailed blind quantitation of myocardial changes (gross and histopathologic). Probucol has shown no identifiable toxicity in mice and rats. In these animals the $\mathrm{LD}_{50}$ (oral) is in excess of five gm/kg of body weight. In chronic studies of two-year duration in rats, no toxicity or carcinogenicily was observed.

From studies in rats, dogs and monkeys, it is known that probucol accumulates slowly in adipose tissue. Approximately 90 percent of probucol administered orally is unabsorbed. For that which is abs
clearance from the body and very little is excreted by way of the kidneys. Myocardial injury was produced in various groups of rats by one of the following procedures: aortic coarctation, coronary
ligation, or cobalt or isoproterenol injiction. After probucol administration, no deleterious efflects related to treatment occurred as measured by survival and microscopic examination of myocardial damage.

Probucol was administered to minipigs beginning ten days before ligation of coronary artery and continued for 60 days post surgery. Challenge with ep
probucol-treated minipigs.

CLINICAL STUDIES: In a multicenter, randomized, double-blind study the LRC-CPPT2, hypercholesterolemic patients density lipoprotein cholesterol reductions greater than those obtained in the placobo grouv treated with diet alone. The
cumulative seven-year incidence of the primary end point- - combined incidence of definite $C H D$ death and or definite nontatal myocardial intarction - was $7 \%$ in the cholestyramine group and $8.6 \%$ in the placebo group. This was a $19 \%$ reduction in ris (Pless than 0.05 , single-tail test) of the primary end point reflecting a $24 \%$ reduction in definite CHO death and a $19 \%$ The subjects included in the study were middle-aged men ( $35-59$ years old) with serum cholesterol levels at least $265 \mathrm{mg} d \mathrm{dl}$
and no previous history of heart disease. It is not clear to what extent these findings can be extrapolated to other segments of and no previous history of heart disease. It is not

The bile acid sequestrant, cholestyramine was used in the above trial. Caution should be exercised in extrapolating thes results to probucol since it differs trom cholestyramine with regard to its mode of action, spectrum of cholesterol-lowerin on morbidity or mortality due to coronary heart disease has not yet been established. Several years may be required before ongoing long-term investigations will resolve this question.

REFERENCES: 1. Consensus Development Panel, Lowering blood cholesterol to prevent heart disease, JAMA 253: 2080-2086, 1985 .
2. The Lipid Research Cinics Propram, The Lipid Research Clinics coronary primary prevention trial results. I. Reduction in
incidence of coronary heart disease, JAMA 251:351-64, 1984. Product information as of January. 1986 MERRELL DOW PHARMACEUTICALS INC 